\title{
O010: A novel immediate pre-operative decolonization strategy reduces surgical site infections
}

\author{
E Bryce $^{1 *}$, T Wong $^{1}$, D Roscoe ${ }^{1}$, L Forrester ${ }^{2}$, B Masri $^{3}$, \\ The Vancouver General Hospital Pre-operative Decolonization Therapy Team ${ }^{1}$ \\ From 2nd International Conference on Prevention and Infection Control (ICPIC 2013) \\ Geneva, Switzerland. 25-28 June 2013
}

\section{Introduction}

Pre-operative decolonization therapy (DcTx) using chlorhexidine ( $\mathrm{CHG}$ ) body washes and/or intranasal mupirocin can reduce surgical site infections (SSI) but compliance is often suboptimal. The effectiveness of a novel approach to immediate pre-operative decolonization therapy using intranasal antimicrobial photodisinfection therapy (PDT) and CHG body wipes in reducing SSIs was assessed.

\section{Objectives}

To determine if immediate pre-operative decolonization using PDT and CHG body wipes reduced SSI rates.

\section{Methods}

Between Sept 1, 2011 and Aug 31st 2012, 3068 elective cardiac, orthopedic, spine, vascular, thoracic and neurosurgery patients were treated with CHG wipes the night prior and day of surgery and received intranasal PDT in the preoperative waiting area. Weekend cases, procedures performed after the pre-operative dayshift, and emergency cases going directly to the operating room were not eligible. SSI surveillance remained unchanged from previous years and patients were followed for a minimum of three months. Results were compared to a historical control group consisting of 12,387 patients over four years and to a concurrent control group of 196 untreated patients.

\section{Results}

A significant reduction in the SSI rate was observed after the intervention [historical-control group $2.7 \%$ and

${ }^{1}$ Medical Microbiology and Infection Prevention and Control,

Vancouver Coastal Health, Vancouver, Canada

Full list of author information is available at the end of the article treatment group 1.6\% ( $\mathrm{p}<0.0001 \mathrm{RR} 1.0114)]$. The risk of having a Staphylococcus aureus infection was higher in the concurrent untreated $(61 \%=11 / 18$ infections $)$ compared to the treated group ( $32 \%=16 / 50$ infections). The reduction in SSIs compared to the historical rates resulted in a cost avoidance of approximately $\$ 1.2$ Million (Can) and would have permitted approximately 140 additional surgeries to be performed.

\section{Conclusion}

The combination of PDT and CHG wipes immediately pre-operatively reduces SSIs and is cost-effective.

\section{Disclosure of interest}

E. Bryce Grant/Research support from The Vancouver Hospital Foundation funded this project. Ondine Biomedical discounted the cost of PDT supplies and provided technical advice but had no role in data collection, analysis or interpretation of results, T. Wong Grant/Research support from The Vancouver Hospital Foundation funded this project. Ondine Biomedical discounted the cost of PDT supplies and provided technical advice but had no role in data collection, analysis or interpretation of results, D. Roscoe Grant/Research support from The Vancouver Hospital Foundation funded this project. Ondine Biomedical discounted the cost of PDT supplies and provided technical advice but had no role in data collection, analysis or interpretation of results, L. Forrester Grant/Research support from The Vancouver Hospital Foundation funded this project. Ondine Biomedical discounted the cost of PDT supplies and provided technical advice but had no role in data collection, analysis or interpretation of results, B. Masri Grant/Research support from The Vancouver Hospital Foundation funded 
this project. Ondine Biomedical discounted the cost of PDT supplies and provided technical advice but had no role in data collection, analysis or interpretation of results.

\section{Author details}

${ }^{1}$ Medical Microbiology and Infection Prevention and Control,

Vancouver Coastal Health, Vancouver, Canada. ${ }^{2}$ Quality and Patient Safety,

Vancouver Coastal Health, Vancouver, Canada. ${ }^{3}$ Department of

Surgery, Vancouver Coastal Health, Vancouver, Canada.

Published: 20 June 2013

doi:10.1186/2047-2994-2-S1-O10

Cite this article as: Bryce et al:: O010: A novel immediate pre-operative decolonization strategy reduces surgical site infections. Antimicrobial Resistance and Infection Control 2013 2(Suppl 1):010.

Submit your next manuscript to BioMed Central and take full advantage of:

- Convenient online submission

- Thorough peer review

- No space constraints or color figure charges

- Immediate publication on acceptance

- Inclusion in PubMed, CAS, Scopus and Google Scholar

- Research which is freely available for redistribution

Submit your manuscript at www.biomedcentral.com/submit 